Research Article

\title{
INTEGRATION OF WIND POWER PLANTS TO THE GRID AND REACTIVE POWER SUPPORT
}

\author{
Onur TAKIR ${ }^{1 *}$, Haydar BAYAR ${ }^{2}$, Erkan DURSUN ${ }^{3}$
}

The conversion of wind energy into electrical energy is one of the most environmentally sustainable methods of energy today. According to statistics published by the World Wind Energy Association, the total capacity of wind turbines installed worldwide at the beginning of 2019 exceeded $598 \mathrm{GW}$. Looking at the situation in Turkey, the number of wind power plants under operation is 180 according to published statistics at January 2019 by the Turkish Wind Energy Association. The total installed capacity of these power plants is 7369.35 MW. By the increasing of wind power capacity, the connection criteria of the power plants which are taken over to the grid become more critical. Although there are systems that are clean, renewable, and reduce external dependence on energy, power quality problems can occur in the grid connections of all wind power plants. In this respect, the grid connection criteria of wind turbines of the countries are essential. The connection requirements of wind turbines in Turkey, on April 22, 2017, revised Turkish Grid Code are determined under Appendix-18. Wind power plants connect to the grid from a medium voltage or high voltage level. At the grid connection point, there are some conditions that the plant must be met like changing wind conditions, switching, fault, etc. These requirements can be summarized as reactive power support, frequency response, contribution to the post-fault system. In this study, the reactive power capacity of a 9x3.6 $M W$ Wind Power Plant to the grid is simulated and investigated.

Keywords: Wind power plant, Turkish grid code, reactive power support

\section{Introduction}

In recent years, with the increasing population growth in the world, the increasing energy demand necessitates the orientation towards alternative energy systems. In this respect, the use of renewable energy sources such as wind, solar, geothermal, and hydroelectric and biomass gains great importance. As of 2017,23.7\% of the electricity consumed around the world is supplied from renewable energy, and wind energy is the third source of this energy [1]. As in the world, interest in renewable energy production in our country continues to increase in recent years. Among renewable energies, wind energy is the sector with the highest investment in the world in terms of installed power and production capacity.

\footnotetext{
${ }^{1}$ Institute of Pure and Applied Science, Marmara University, Kadiköy, Istanbul, Turkey (onurtakir@gmail.com)

2 The Department of Marine Engineering Operations, Yildiz Technical University, Besiktas, Istanbul, Turkey (hbayar@yildiz.edu.tr) iD https://orcid.org/0000-0002-4086-938X

3 Faculty of Technology, Department of Electrical and Electronics, Marmara University, Kadiköy, Istanbul, Turkey, (erkandursun@marmara.edu.tr) Dhttps://orcid.org/0000-0002-7914-8379
} 
As of 2016, the installed capacity of wind power plants in the world is $486.8 \mathrm{GW}$, and it is predicted that by 2021 there will be $817 \mathrm{GW}$ wind installed power in the world [2].

As of July 2018, 7.7\% of Turkey's installed power consists of power plants based on wind energy [2]. According to the International Renewable Energy Agency (IRENA), Turkey's installed capacity of wind power reached $6516 \mathrm{MW}$ in 2017 [3]. Wind energy power plants of 2018 of the share of electricity generation in Turkey are shown in Figure 1.

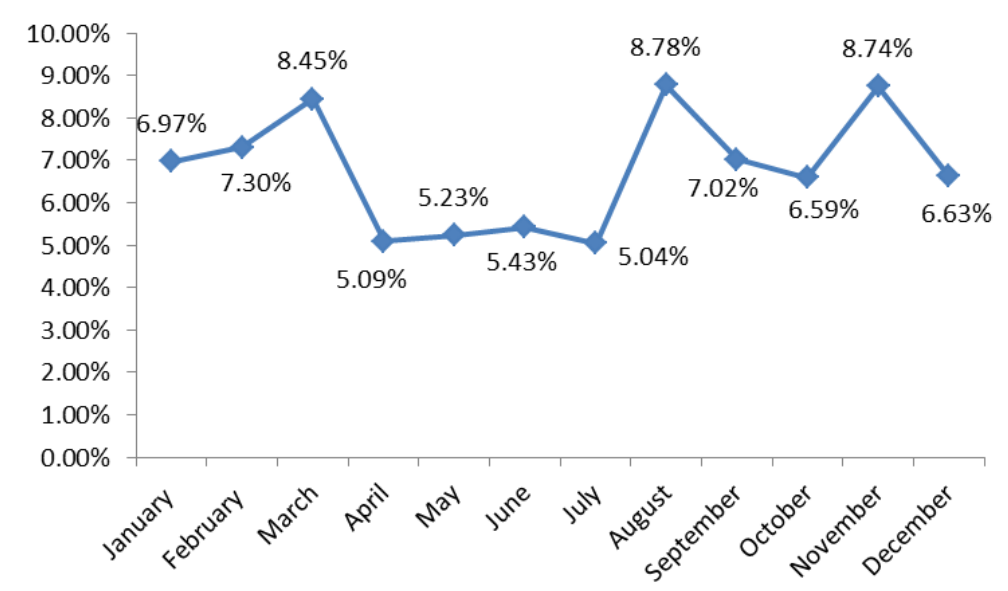

Figure 1. The share of Wind Power Plants in electricity generation in Turkey, 2018

Table 1. Turkey's renewable energy targets and resource-based energy production [MW]

\begin{tabular}{lcccc}
\hline Renewable Energy Type & 2015 & 2017 & 2019 & 2023 \\
\hline Hydroelectric & 25.526 & 28.763 & 32.000 & 34.000 \\
Wind & 5.660 & 9.549 & 13.308 & 20.000 \\
Solar & 300 & 1.800 & 3.000 & 5.000 \\
Geothermal & 412 & 559 & 706 & 1.000 \\
Biomass & 377 & 530 & 683 & 1.000 \\
\hline
\end{tabular}

According to the renewable energy targets shown in Table 1 and targeted by the Ministry of Energy and Natural Resources, it is aimed to increase the wind power installed capacity to $20 \mathrm{GW}$ in 2023. In other words, as of the end of 2017, it is seen that the current installed capacity of wind energy is planned to be doubled. When the wind energy capacity is increased rapidly, the grid connection criteria of the power plants become more critical. The connection requirements of wind turbines in Turkey, on April 22, 2017, revised Turkish Grid Code are determined under Appendix-18. According to the grid criteria in the Electricity Market Grid Regulation, dynamic and static analyzes are needed to provide active power control, frequency response, reactive power capacity, and reactive power support in terms of the effect of wind turbines on the grid [4].

\section{Contribution of Wind Power Plant to System after Post-Fault}

During the period in which the phase-to-phase voltage at the transmission or distribution system connection point remains in zones 1 and 2 given in Figure 2, the relevant generation facilities must remain connected to the grid in case of voltage drops in any phase or all phases. 


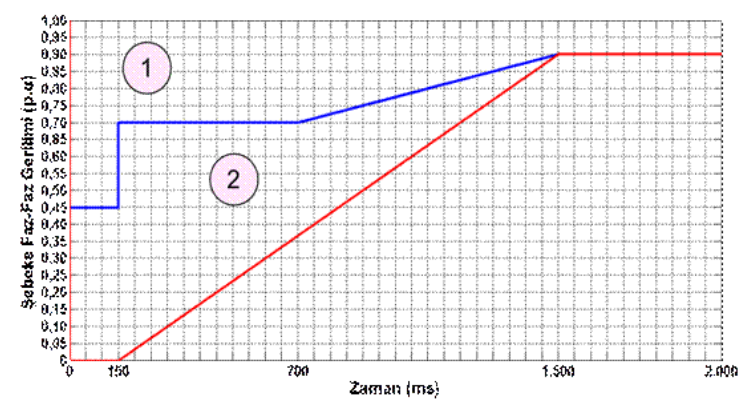

Figure 2. The line to line voltage in transmission or distribution at a system connection point

The main purpose shown in Figure 2 is to prevent wind power plants from unnecessarily leaving the system in case of any failure according to the conditions given in the graph and to ensure that the protection priority is given to other protective equipment. According to Figure 2, there are two separate cases [5]. In case 1 , phase voltage continues to remain in the system for $150 \mathrm{~ms}$ if it drops to $0.45 \mathrm{pu}$, if the grid voltage goes to $0.70 \mathrm{pu}$ at the end of $150 \mathrm{~ms}$, it will remain in the system for up to $700 \mathrm{~ms}$ and finally the grid voltage up to $0.90 \mathrm{~ms}$ If it reaches the pu value, it should remain in the system. 2 . In the case of $150 \mathrm{~ms}$ mains voltage down to zero, even if the system does not exits, between $150 \mathrm{~ms}$ and 1500 $\mathrm{ms}$ to $0.90 \mathrm{pu}$ value of the grid voltage increases linearly to reach the wind power must continue to be connected to the interconnected grid. In the cases below zone 2, the wind power plant is not expected to remain connected to the system. The post-fault contribution to the system is entirely related to the design of the controller, which ensures that the wind turbine remains connected to the grid during mains failure. The post-fault contribution to the system also determines how to correct the voltage after the mains failure [6]. In cases where the voltage drop during the fault remains in zone 1, the production plant's active power must be increased by at least $20 \%$ of the nominal active power per second immediately after the fault is cleared, to reach the maximum active power value that can be generated. In case the voltage drop during the fault remains in zone 2, the active power of the generation facility should increase by at least $5 \%$ of the nominal active power immediately after the fault is cleared and reach the maximum active power value that can be generated. Voltage fluctuations $(0.9 \mathrm{pu}-1.1 \mathrm{pu})$ up to $\pm 10 \%$ at the grid connection point are normal operating conditions. In case of voltage fluctuations greater than $\pm 10 \%$ in the event of failure in the mains connection point, each wind turbine generator and/or each inverter in the plants shall be capable of inductive or capacitive levels up to $100 \%$ of the rated current without exceeding the designed transient ratings and provide maximum reactive current support. This transient should reach the maximum reactive current support value within $60 \mathrm{~ms}$ with a $10 \%$ error margin and be maintained for 1.5 seconds.

\subsection{Active Power Control}

Active power control can be carried out in emergencies defined in Article 63 of the Electricity Market Grid Regulation in wind generation facilities connected to the transmission system. The active power output of the generation facility should be automatically controlled between $20 \%$ and $100 \%$ of the available power of the plant under the current conditions with the signals to be sent by the Turkish Electricity Transmission Corporation (TEIAS) when necessary. 


\subsection{Reactive Power Control}

Wind power-based generation facilities must be able to operate continuously at each point for reactive power values within the boundaries indicated by dark blue lines in Figure 3 at the transmission or distribution system connection point.

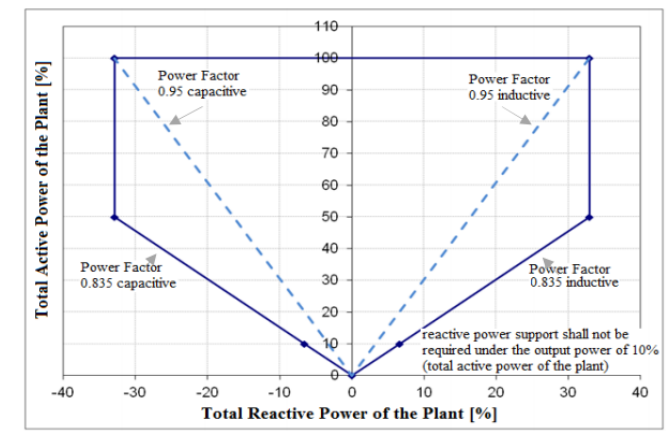

Figure 3. Wind power plant reactive power capacity curve [7]

Wind power plants should react proportionally to changes in grid connection voltage. The voltage drop value should be between $2-7 \%$. The wind power plant under normal operating conditions should start responding to a sudden change in the transmission grid connection voltage within $200 \mathrm{~ms}$ at the latest. The reactive output power should reach $90 \%$ of the equilibrium value within 1 second.

\section{Reactive Power Capacity Analysis: A Case Study}

In this study, the reactive power capacity of a Wind Power Plant with 9x3.6 MW wind turbines can be provided as an example. According to the reactive power capacity curve of the wind power plant given in Figure 3, the reactive power values that the power plant can supply to the grid are analyzed with EDSA Paladin DesignBase software. EDSA program can perform engineering calculations such as short circuit, relay coordination, arc flash, and load flow [8-10]. Load flow calculations are used to analyze power systems under stable system conditions. In power systems, analyzes are made for the current operating status and planning status. Steady-state is the state in which all variables and parameters in the system operate continuously during the observation period. In load flow analysis, active, reactive power values, current value, voltage, how many lines, and transformers are loaded are analyzed [11-12].

The calculations of the designed power plant were carried out to be connected to the TEIAS transmission line of $154 \mathrm{kV}$ high voltage level. In the power plant, which consists of $93.6 \mathrm{MW}$ wind turbines, the voltage of wind turbines is modeled as $0.66 \mathrm{kV}$. It is planned that the wind turbines joining at $34.5 \mathrm{kV}$ bus bar will connect to the interconnected network with 154 / $34.5 \mathrm{kV}$ TEIAS transformer. For the technical information of the turbines, NORDEX's document "Reactive Power Capability WTG K08 Delta" was used (Figure 4). 

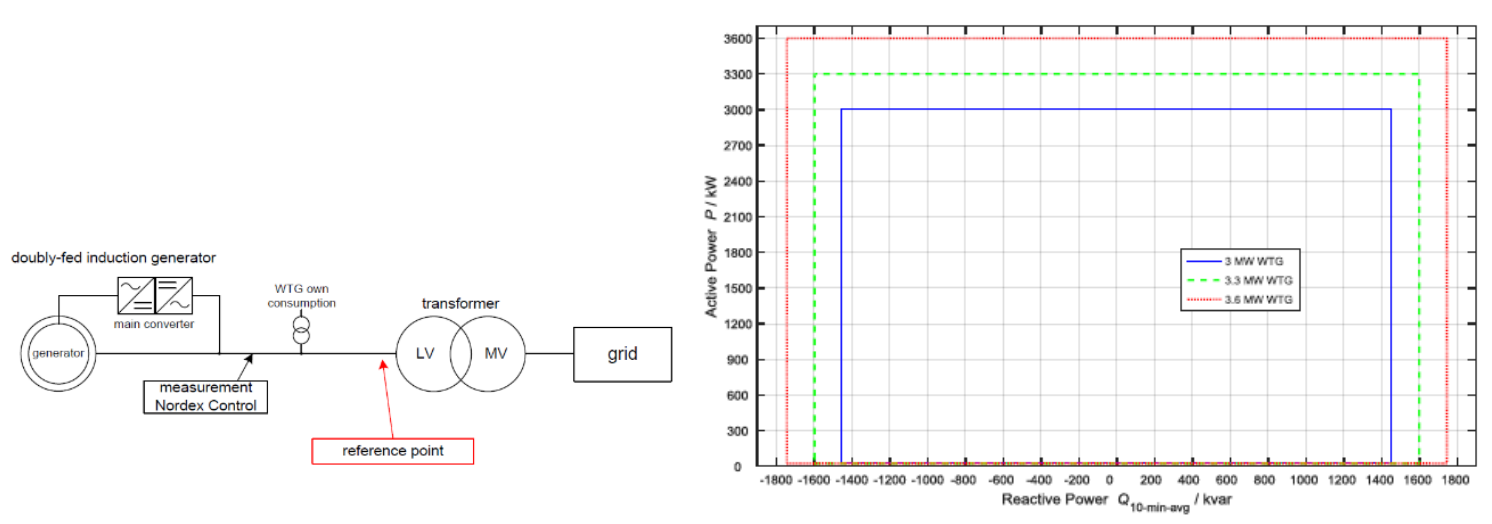

Figure 4. Nordex 3.6 MW turbine model and turbine active/reactive power change figure

According to the wind power plant, reactive power capacity curve given in Figure 2, 6 different scenarios were examined. These scenarios are provided in the following Table 2. The scenarios are based on the corner points in the graph given in Figure 2. In other words, the scenarios where the power plant operates at $1 \mathrm{pu} 0,5 \mathrm{pu}$ and $0,1 \mathrm{pu}$ power separately in inductive and capacitive operating conditions are considered.

Table 2. Load flow analysis scenarios

\begin{tabular}{|c|c|c|c|}
\hline \multirow{2}{*}{$\frac{\text { Scenarios }}{\text { No }}$} & & \multicolumn{2}{|c|}{ NORDEX 3.6 MW } \\
\hline & & $\mathrm{P}[\mathrm{kW}]$ & $\mathrm{Q}$ [kVar] \\
\hline 1 & $\mathrm{P}_{100 \%}$ End. & 3600 & 1744 \\
\hline 2 & $\mathrm{P}_{50 \% \text { End. }}$ & 1800 & 1744 \\
\hline 3 & $\mathrm{P}_{10 \%}$ End. & 360 & 1744 \\
\hline 4 & $\mathrm{P}_{100 \%}$ Cap. & 3600 & -1744 \\
\hline 5 & $\mathrm{P}_{50 \%}$ Cap. & 1800 & -1744 \\
\hline 6 & $\mathrm{P}_{10 \% \text { Cap. }}$ & 360 & -1744 \\
\hline
\end{tabular}

The total active power is $9 \times 3.6=32.4 \mathrm{MW}$ installed capacity when 9 power plants with 3.6 MW wind turbines are inspected. According to the installed capacity, the inductive or capacitive generation of 10.65 MVAr is required in the $32.4 \mathrm{MW}$ and 16.2 MW active power generation range. It must provide reactive power support of 2.14 MVAr at $0.1 \mathrm{pu}, 3.24 \mathrm{MW}$ active power generation point.

Scenario 1: $\mathrm{P}=3600 \mathrm{~kW}, \mathrm{Q}=1744 \mathrm{~kW}$ (Capacitive)

In this scenario, in case of turbines generate $100 \%$ active power and capacitive operation, 31,85 MW active power and 11,03 MVAr reactive power generation in $154 \mathrm{kV}$ TEIAS bus bar are calculated (Figure 5). 


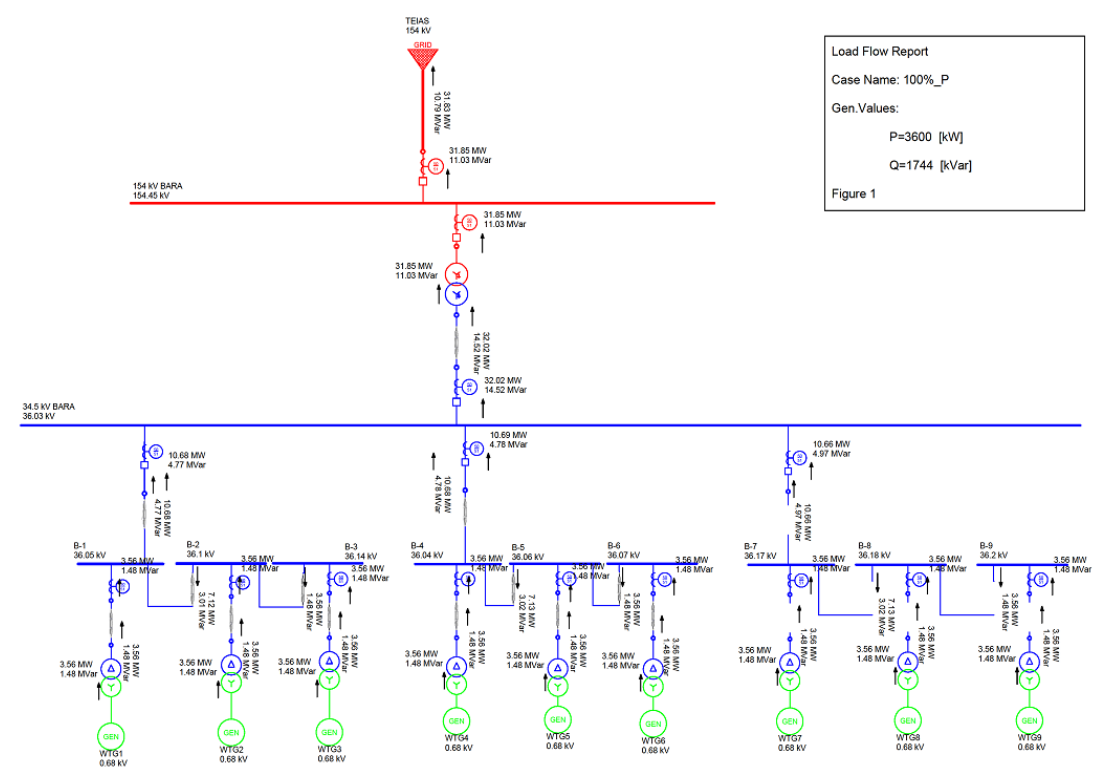

Figure 5. Scenario 1 results

Scenario 2: $\mathrm{P}=1800 \mathrm{~kW}, \mathrm{Q}=1744 \mathrm{~kW}$ (Capacitive)

In this scenario, when the turbines generate $50 \%$ active power and capacitive operation, 15.95 MW active power, and 14.37 MVAr reactive power generation at $154 \mathrm{kV}$ TEIAS bus bar are calculated (Figure 6).

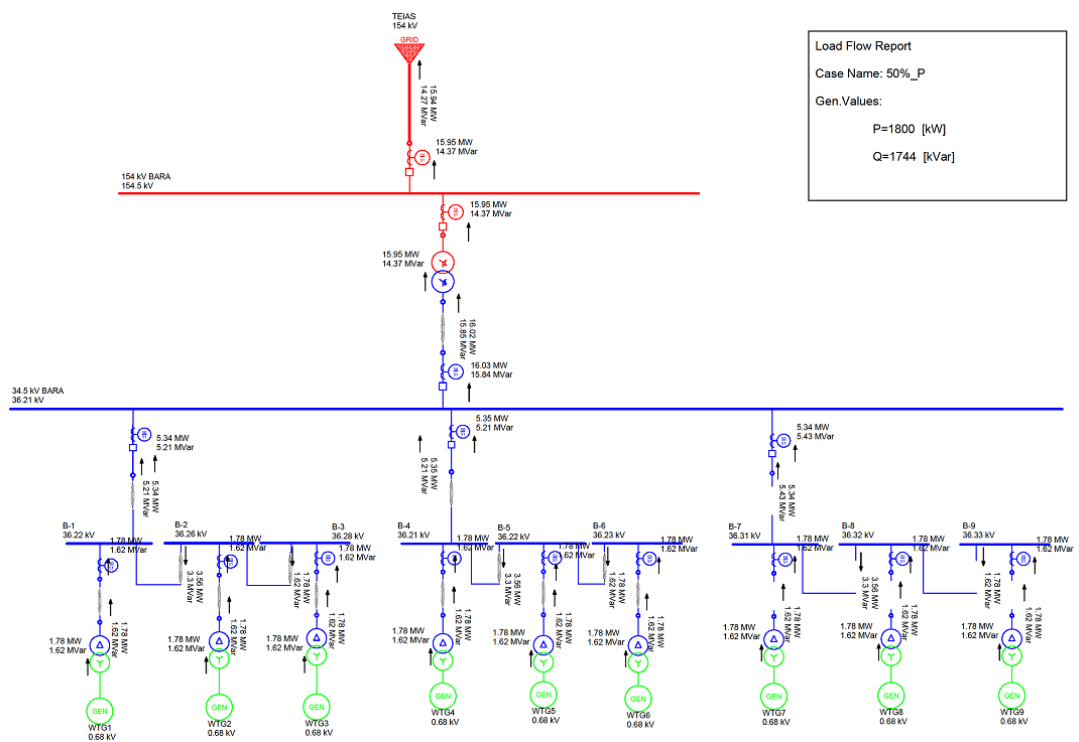

Figure 6. Scenario 2 results

Scenario 3: $\mathrm{P}=360 \mathrm{~kW}, \mathrm{Q}=1744 \mathrm{~kW}$ (Capacitive)

In this scenario, in case of turbines generate $10 \%$ active power and capacitive operation, $3.08 \mathrm{MW}$ active power, and 15.42 MVAr reactive power generation in $154 \mathrm{kV}$ TEIAS bus is calculated (Figure 7). 


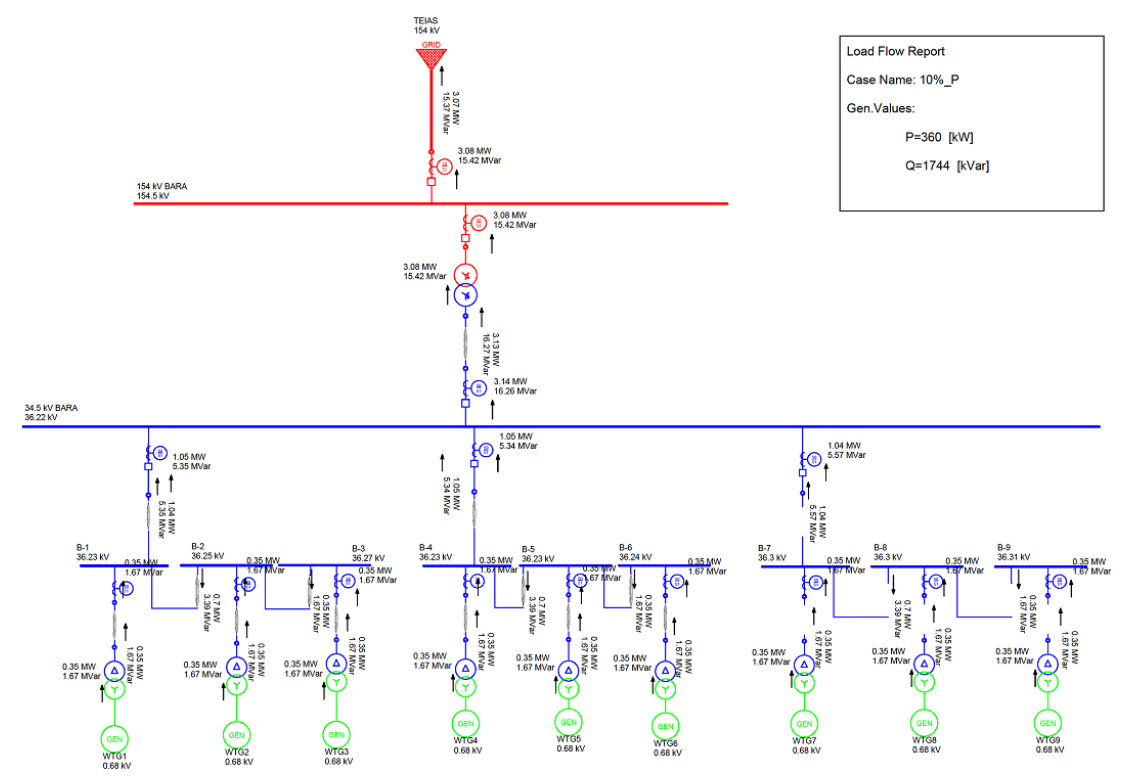

Figure 7. Scenario 3 results

Scenario 4: $\mathrm{P}=3600 \mathrm{~kW}, \mathrm{Q}=-1744 \mathrm{~kW}$ (Inductive)

In this scenario, when the turbines generate $100 \%$ active power and capacitive operation, 31.75 MW active power and -22.02 MVAr reactive power generation at $154 \mathrm{kV}$ TEIAS bus bar is calculated (Figure 8).

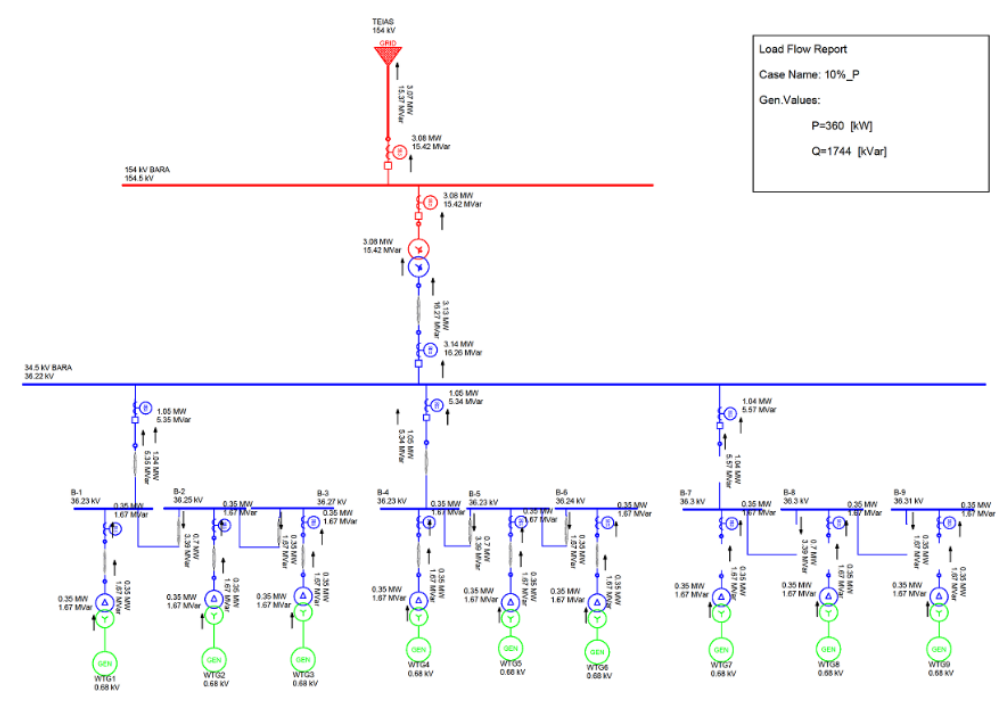

Figure 8. Scenario 4 results

Scenario 5: $\mathrm{P}=1800 \mathrm{~kW}, \mathrm{Q}=-1744 \mathrm{~kW}$ (Inductive)

In this scenario, in case of turbines generate 50\% active power and capacitive operation, 15,92 MW active power and -17.69 MVAr reactive power generation in $154 \mathrm{kV}$ TEIAS bus bar are calculated (Figure 9). 


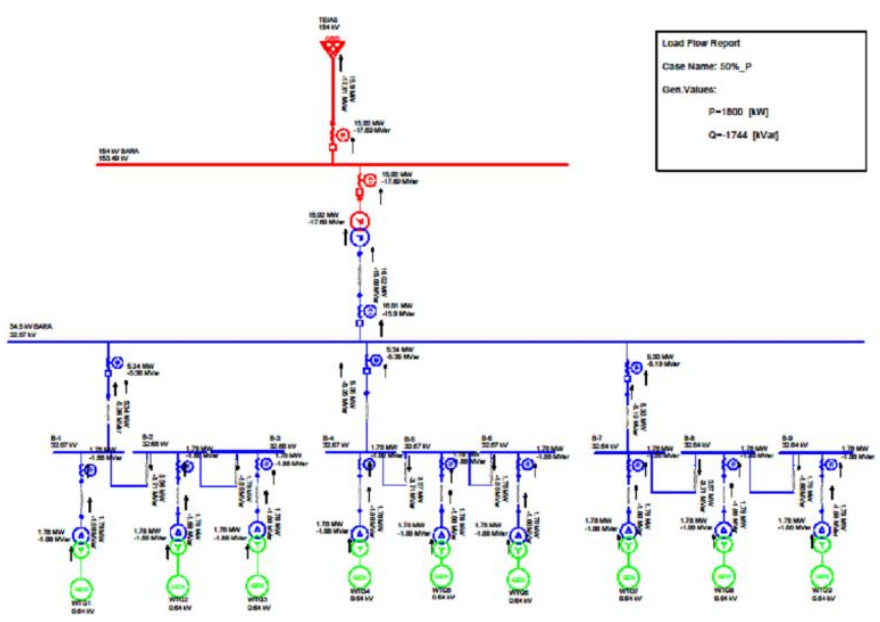

Figure 9. Scenario 5 results

Scenario 6: $\mathrm{P}=360 \mathrm{~kW}, \mathrm{Q}=-1744 \mathrm{~kW}$ (Inductive)

In this scenario, in case of turbines generate $10 \%$ active power and capacitive operation, $3.07 \mathrm{MW}$ active power and -16.34 MVAr reactive power generation in $154 \mathrm{kV}$ TEIAS bus bar is calculated (Figrue $10)$.

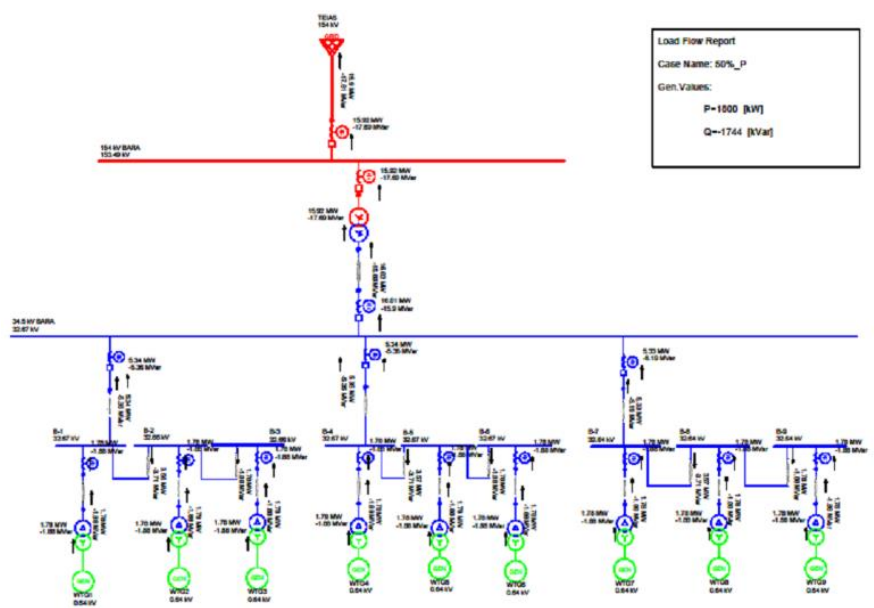

Figure 10. Scenario 6 results

The reactive power capacity curve of the analyzed wind power plant with an installed capacity of 32.4 MW according to 6 different scenarios is shown in Figure 11. As seen in this curve, the wind farm, which is examined as an example, can meet the minimum reactive power support conditions demanded by TEIAS at every point.

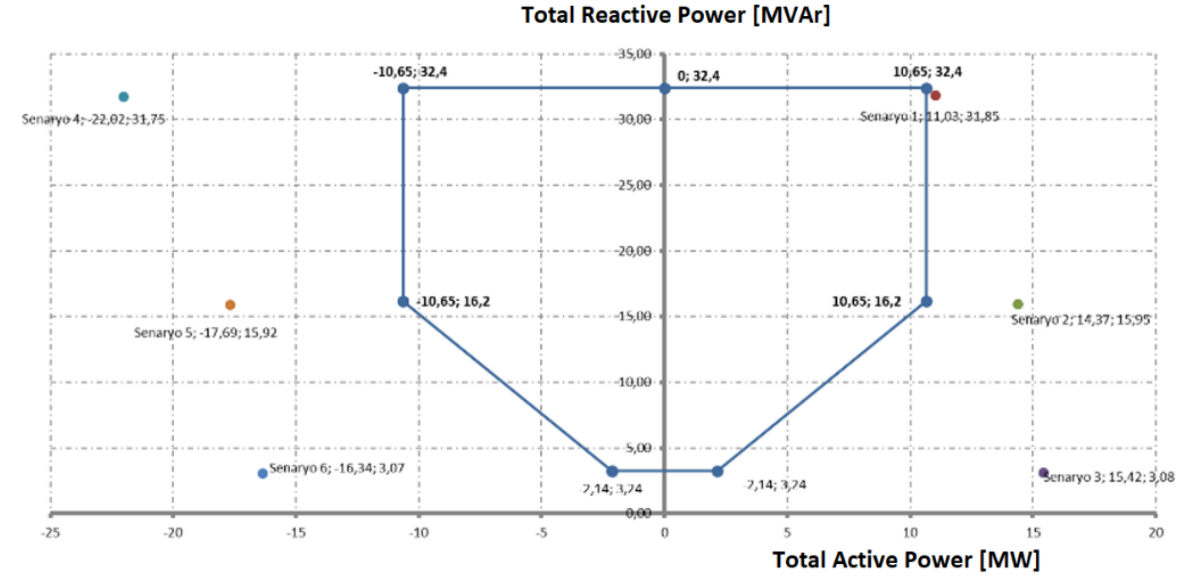

Figure 11. Simulation results for the wind power plant reactive power capacity 


\section{Conclusions}

In this study, the conditions that the $32.4 \mathrm{MW}$ wind power plant to be connected to the interconnected grid at $154 \mathrm{kV}$ voltage level, must comply with the Turkish Grid Code are examined. Load flow analysis of the power plant has been performed and the compliance of the results of the analysis with the Appendix-18 of the Turkish Grid Code has been checked. These analyzes are also required for all wind farms planned to be established. If TEIAS criteria cannot be met according to the results of the analyzes, it may be planned to install a reactor or capacitor feeder in the plant for reactive power support. Load flow analysis, short circuit analysis, harmonic and flicker analysis, dynamic analysis and grounding analysis should be carried out meticulously during the design phase of wind farms. In this way, problems to be encountered in grid connections of wind power plants can be identified and measures can be taken.

\section{References}

[1] Republic of Turkey Ministry of Energy and Natural Resources, http://www.enerji.gov.tr/trTR/Sayfalar/Elektrik/ Accessed on May 16, 2019.

[2] Global Wind Energy Council, https://gwec.net/publications/global-wind-report-2/global-windreport-2016/ Accessed on May 10, 2019.

[3] International Renewable Energy Agency, https://irena.org/publications/2018/Jul/RenewableEnergy-Statistics-2018 / Accessed on May 26, 2019.

[4] Turkey Legal Gazette, http://www.resmigazete.gov.tr/eskiler/2017/04/20170422-8-1.pdf/ Accessed on June 01, 2019.

[5] Demirol, E., Demirol, T. (2015). Simulation Modeling for Network Connection Analysis of Wind Power Plants. Gazi Journal of Engineering Sciences, 1(3), 351-368.

[6] Rona, B., Integration of Wind Power Plants to Power System and Analysis According to Grid Regulation. MSc.Thesis, Istanbul Technical University, 2014.

[7] Uzun, S., et. al (2015). Integration criteria of Turkish wind energy generation plants and assessment of the criteria by analysis. 9th International Conference on Electrical and Electronics Engineering (ELECO), Bursa, Turkey, 1039-1042.

[8] http://www.poweranalytics.com/introducing-designbase-6-0/ Accessed on June 11, 2019

[9] Kiliç, H., Khaki, B., Gumuş, B., Yilmaz, M., \& Asker, M. E. (2018, November). Stability Analysis of Islanded Microgrid with EVs. In 2018 Smart Grid Conference (SGC) (pp. 1-5). IEEE.

[10] Yilmaz, M. (2018). Real measure of a transmission line data with load fore-cast model for the future. Balkan Journal of Electrical \& Computer Engineering (BAJECE), Vol 6, No 2, pp.141-145.

[11] Samancioğlu, G., Wind Basin Planning and Modeling of the Effects of Wind Power Plants to the Network with Digilent Program. MSc.Thesis, Gazi University, 2014.

[12] Tür, M. R. (2019). The Impact of Emerging Renewable Energy on Capacity Mechanisms in Power Systems and Expert Opinion. Balkan Journal of Electrical and Computer Engineering, 7(3), 319-325. 